Pricing and Supply Chain Transparency to

Conscientious Consumers

Marco Bertini, Stefan Buehler and Daniel Halbheer

November 2020 Discussion Paper no. 2020-20

School of Economics and Political Science, Department of Economics 


$\begin{array}{ll}\text { Editor: } & \text { Vanessa Pischulti } \\ & \text { University of St.Gallen } \\ & \text { School of Economics and Political Science } \\ & \text { Department of Economics } \\ & \text { Müller-Friedberg-Strasse 6/8 } \\ & \text { CH-9000 St.Gallen } \\ & \text { Phone +4171 224 23 07 } \\ & \text { Email seps@unisg.ch } \\ & \text { School of Economics and Political Science } \\ & \text { Department of Economics } \\ & \text { University of St.Gallen } \\ \text { Publisher: } & \text { Müller-Friedberg-Strasse 6/8 } \\ & \text { CH-9000 St.Gallen } \\ & \text { Phone +41 71 224 23 07 } \\ & \text { http://www.seps.unisg.ch }\end{array}$




\title{
Pricing and Supply Chain Transparency to Conscientious Consumers ${ }^{1}$
}

\author{
Marco Bertini, Stefan Buehler and Daniel Halbheer ${ }^{\dagger}$
}

\author{
Author's address: $\quad$ Stefan Buehler \\ Institute of Economics (FGN-HSG) \\ University of St.Gallen \\ Varnbüelstrasse 19 \\ $\mathrm{CH}-9000$ St.Gallen \\ Phone $\quad+41712242303$ \\ Email_stefan.buehler@unisg.ch \\ Website https://fgn.unisg.ch/de/chairs/stefan-buehler
}

\footnotetext{
${ }^{1}$ We thank Anthony Dukes, Rodolphe Durand, Thomas Epper, Samuel Haefner, Rick Harbaugh, Maarten Janssen, Heiko Karle, Oded Koenigsberg, Philemon Kraehenmann, Song Lin, Dina Mayzlin, Martin Peitz, and seminar participants at the Annual Meeting of the Committee for Industrial Economics 2018 (Vienna), EARIE 2018 (Athens), EMAC 2018 (Glasgow), IIOC 2018 (Indianapolis), INFORMS Marketing Science Conference 2018 (Philadelphia), SSES 2018 (St.Gallen), the University of Fribourg, HEC Paris, and the USC Marshall for helpful comments and suggestions.

†Marco Bertini: ESADE, Universitat Ramon Llull, Avinguda de la Torre Blanca, 59, 08172 Sant Cugat del Vallès, Spain (marco.bertini@esade.edu).

Stefan Buehler: University of St.Gallen, Institute of Economics (FGN-HSG); CESifo Munich.

Daniel Halbheer: HEC Paris, Marketing Department, 1 rue de la Libération, 78351 Jouy-en-Josas Cedex, France (halbheer@hec.fr); member of the CNRS unit GREGHEC, UMR CNRS 2959.
} 


\begin{abstract}
This paper studies how a firm should make pricing and transparency decisions when consumers care about supply chain characteristics. We first show how preferences that account for price and unit cost constrain the firm's pricing power and profit. Surprisingly, we find that the firm may be forced to sell at unit cost under markup aversion. Next, we assume that consumers are uncertain about unit cost and show that, in a pooling equilibrium, it is optimal for both the low-cost and high-cost firm to conceal its unit cost if the cost of disclosure exceeds the corresponding gain from demand expansion. Third, we show that in a separating equilibrium it is optimal for the high-cost firm alone to engage in cost transparency when the increase in product market profit exceeds the cost of disclosure. Finally, we establish the conditions under which it is optimal for the firm to disclose other details of the supply chain including provenance, labor policies, and environmental footprint.
\end{abstract}

\title{
Keywords
}

Conscientious consumption, cost transparency, operational transparency, pricing, referencedependent preferences

\section{JEL Classification}

D42, L21, M2, M3 


\section{Introduction}

Consumers can be considered "conscientious" when they care not only about a product's intrinsic features and price, but also about the impact of their purchases on society and the environment. Conscientious consumers want reassurance that firms act responsibly, and they are willing to boycott specific products when something is amiss-a phenomenon originally known as "dollar voting" (Buchanan 1954). In response to this pressure, many firms consider disclosing information about their supply chains, from the cost of bringing a product to market to details about provenance, labor policies, and environmental footprint (Marshall et al. 2016; Sodhi and Tang 2019). For instance, sports and fashion labels often publish cost information and details on work conditions and environmental impact. Similarly, pharmaceutical companies provide cost information to justify "ethical margins," consumer electronics brands do the same to counter product "teardowns," and airlines and car manufacturers commit publicly to responsible sourcing. However, it is fair to say that the impact of engaging in supply chain transparency on firm performance is not very well understood.

The goal of this paper is to study a firm's pricing and transparency decisions in the face of conscientious consumers. To this end, we develop an analytical framework in which a profit-maximizing firm sets the price for its product and decides whether or not to disclose characteristics of the supply chain. Consumers have reference-dependent preferences that account for these characteristics, and suffer from a psychological loss if they are considered substandard. This loss translates into a higher perceived price, which in turn affects the consumers' purchase decisions and firm p rofit. We first study cost transparency, as conscientious consumers often care about margins. Next, we adapt our analytical framework to study operational transparency, as conscientious consumers also care about ethical and sustainable sourcing. The key feature of our analytical framework is that price and disclosure decisions are determined endogenously by the choices of the firm and consumers, accounting for the latter's beliefs about the supply chain.

We derive several key results from our analysis. First, we study the optimal pricing policy when consumers know the firm's unit cost. We generalize the standard inverse- 
elasticity pricing rule and show that consumer conscientiousness constrains the firm's pricing power and profit, which r eflects du al en titlement ( $\mathrm{K}$ ahneman, Kn etsch and Tversky 1986). Next, we show that the impact of a change in the reference standard and the strength of reference dependence on the optimal price and profit is generally ambiguous. We illustrate these findings in a setting with linear demand and a reference margin. Surprisingly, we find that the firm is forced to sell at unit cost if consumers have markup aversion and strong reference dependence.

Second, we study optimal price and cost disclosure decisions when consumers are uncertain about unit cost and form an expectation of the psychological loss based on firm decisions. We show that there exists a perfect Bayesian equilibrium in pure strategies such that both a high-cost and a low-cost firm charge the same price and conceal their unit cost when disclosure is sufficiently expensive. Intuitively, in such a pooling equilibrium the high-cost firm could benefit from communicating its unit cost because it reduces the psychological loss imparted on consumers and boosts demand, but the resulting increase in profit is smaller than the cost of disclosure. However, if the cost of disclosure is sufficiently low, then there exists a unique separating perfect Bayesian equilibrium such that the high-cost firm communicates its unit cost and the low-cost firm does not, and the profitmaximizing price of each firm is determined according to the pricing policy with known unit cost. Importantly, these results highlight that consumer conscientiousness alone is not sufficient for cost transparency to emerge in the marketplace: what matters is the trade off between the expansion of product market profit resulting from cost transparency and the cost of disclosure.

Third, we study a setting where the firm can communicate specific, prominent features of the production process rather than a summary statistic such as unit cost. We show that, if the cost of disclosure is sufficiently low compared to the corresponding gain from demand expansion, then there exists a unique separating perfect Bayesian equilibrium in pure strategies such that the high-standard firm is transparent about its operations but the low-standard firm is $\mathrm{n}$ ot. This result provides an explanation for the observation that operational transparency in complex supply chains with many (successive) upstream 
suppliers is rare: Disclosing multiple characteristics increases the cost of disclosure because each link in the supply chain needs to be certified and disclosed, which is a challenging task and may lead to consumer backlash if any weakness is overlooked.

Overall, our paper contributes to the growing management literature on transparency. A recent review article by Sodhi and Tang (2019) points to a lack of research tying consumer attitudes toward transparency to firm decisions and performance. We provide an analytical framework that, to the best of our knowledge, is the first to synthesize and expand independent streams of research on cost transparency (Jiang, Sudhir and Zou 2020; Lim et al. 2018; Mohan, Buell and John 2020) and operational transparency (Buell and Norton 2011; Buell, Kim and Tsay 2020). At the same time, we complement experimental evidence that supply chain transparency can build goodwill among consumers and shape purchase intentions (Buell and Norton 2011; Kim and Tsay 2020; Mohan, Buell and John 2020) by clarifying how transparency drives sales and profit. We also add to analytical work that studies how cost transparency drives intertemporal price discrimination and purchase decisions (Jiang, Sudhir and Zou 2020) or acts as an exogenous shift in demand by increasing the firm's trustworthiness (Lim et al. 2018) by showing how price and disclosure decisions jointly determine consumer valuations. By operationalizing the impact of transparency via a psychological reference point, our research differs from articles on the communication of intrinsic product features (Dranove and Jin 2010; Guo and Jiang 2016; Guo and Zhao 2009) and the related question of product labeling (Bonroy and Lemarié 2012; Harbaugh, Maxwell and Roussillon 2011), and it also differs from articles on greenwashing in sustainability campaigns (Wu, Zhang and Xie 2020). By focusing on truthful disclosure (Milgrom 2008) to conscientious consumers, our research further differs from strategic disclosure with the goal of exploiting naive consumers in an “aftermarket" (Armstrong and Vickers 2012; Atefi et al. 2020).

Our paper also adds an analytical perspective to the growing literature in marketing on responsible consumption and the so-called transformative consumer research movement (Giesler and Veresiu 2014). In addition, we contribute to previous work on reference prices (Amaldoss and He 2018; Bruno, Che and Dutta 2012; Zhou 2011), as well as 
work on judgments about price fairness based on inequity aversion (Guo 2015; Guo and Jiang 2016), markup aversion (Eyster, Madarász and Michaillat 2020; Rotemberg 2011), or dual entitlement (Bolton and Alba 2006; Chen et al. 2017; Xia, Cox and Monroe 2004), by allowing for consumer heterogeneity in product valuations and capturing the interaction with supply chain transparency. Our research further relates to studies on price partitioning, which entails breaking an expense down into a set of component charges, presented simultaneously (Bertini and Wathieu 2008; Morwitz, Greenleaf and Johnson 1998) or “dripped" over time (Santana, Dallas and Morwitz 2020), by construing supply chain transparency as a means to inform consumers about the cost and margin components of a price. Finally, our paper is related to the literature on the impact of consumer loss aversion on pricing (Heidhues and Kőszegi 2008; Karle, Kirchsteiger and Peitz 2015; Karle and Peitz 2014), which considers expectations-based reference points regarding price and intrinsic product attributes. Abstracting from uncertainty about preferences and price, we consider loss aversion regarding exogenous psychological reference points (Amaldoss and He 2018; Guo and Jiang 2016; Guo 2015), which allows us to perform comparative statics on the reference standard and the strength of reference dependence.

The remainder of the paper is organized as follows. Section 2 introduces the analytical framework. Section 3 studies the pricing decision when conscientious consumers know the firm's unit c ost. Section 4 introduces cost uncertainty and studies optimal pricing and cost disclosure decisions. Section 5 extends the analysis to operational transparency. Section 6 concludes and offers directions for future research.

\section{Analytical Framework}

Consider a firm that offers a product (or service) to consumers at price $p \geq 0$, given its unit $\operatorname{cost} c \geq 0$. Consumers are conscientious in the sense that they have reference-dependent preferences, evaluating the product based not only on its price $p$ and the valuation of its intrinsic features $v$, but also on the nature of the supply chain, captured for the moment by the known unit $\operatorname{cost} c$. We start with unit cost because it provides a simple summary statistic for the nature of the supply chain. Knowing $c$ allows consumers to infer the 
firm's markup and profit. Consumers can learn about the unit cost directly from the firm or indirectly from external agencies such as Consumer Reports that act to promote transparency in the marketplace. In Section 5, however, we will turn our attention to specific characteristics of the supply chain such as labor conditions and environmental footprints. The unobserved valuation $v \in[0, \infty)$ of the intrinsic features is distributed independently across consumers according to the cumulative distribution function $F(v)$, with the associated density function $f(v)>0$ for all $v$.

A consumer derives utility

$$
v-p-L(p, c ; r, \lambda)
$$

where $L(p, c ; r, \lambda) \geq 0$ captures the psychological loss (measured in monetary terms) if the outcome of the transaction falls short of the standard $r \geq 0$, with $\lambda \geq 0$ indicating the strength of reference dependence. Letting subscripts denote partial derivatives, the loss function satisfies the following assumption.

Assumption 1. The psychological loss function $L(p, c ; r, \lambda)$ is piece-wise differentiable and satisfies $L_{p} \geq 0, L_{c} \leq 0, L_{r} \leq 0$, and $L_{\lambda} \geq 0$.

Assumption 1 states that the psychological loss increases in price and decreases in unit cost, reflecting markup or profit aversion by consumers (Bhattacharjee, Dana and Baron 2017; Eyster, Madarász and Michaillat 2020). In line with the dual entitlement principle (Kahneman, Knetsch and Tversky 1986), this loss decreases when the reference standard is less stringent (a higher $r$ ) and increases when consumers are more sensitive to deviations from that standard (a higher $\lambda$ ). To simplify exposition, we henceforth suppress the dependence of the loss function on $r$ and $\lambda$.

By normalizing the utility of the outside option to zero, a conscientious consumer purchases the product if the valuation of the intrinsic features $v$ exceeds the purchase price including the psychological loss, or "perceived price," $p+L(p, c)$. Therefore, the demand for the product is derived as

$$
D(p, c)=\int_{\bar{v}(p, c)}^{\infty} d F(v)=1-F(\bar{v}(p, c))
$$


where $\bar{v}(p, c)$ denotes the valuation of the consumer who is indifferent between purchasing the product or choosing the outside option. Consumer conscientiousness implies that demand depends on price and unit cost rather than price alone. Specifically, Assumption 1 implies that demand is decreasing in price $p$ and increasing in unit cost $c$. To put additional structure on demand, we impose the following assumption:

Assumption 2. The demand function $D(p, c)=1-F(\bar{v}(p, c))$ is log-concave in price $p$ wherever it is differentiable.

Assumption 2 implies that the demand function is "well behaved," such that standard profit-maximization techniques can be applied (Caplin and Nalebuff 1991). Our first result shows how consumer conscientiousness affects the price elasticity of demand and, therefore, the pricing power of the firm. To facilitate exposition, all proofs are relegated to the Appendix.

Lemma 1. If $L(p, c)>0$, then consumer conscientiousness increases the price elasticity of demand $\varepsilon(p, c) \equiv-\frac{p D_{p}(p, c)}{D(p, c)}$.

Lemma 1 shows that a price increase has two effects if consumer conscientiousness creates a psychological loss at the prevailing price and cost levels. First, a higher price directly increases the perceived price $p+L(p, c)$, and therefore the price elasticity of demand because of log-concavity. This is the standard effect of a price increase. Second, a higher price indirectly increases the perceived price via the psychological loss, a new channel for price to affect demand. This result is consistent with the empirical finding that fairness concerns make demand more elastic (Anderson and Simester 2008).

\section{Pricing With Known Cost}

This section studies the impact of consumer conscientiousness on pricing and firm profit in the case where consumers know the unit $\cos t c$. The results are illustrated in a setting with linear demand and a reference margin. 


\subsection{General Pricing Policy}

The firm chooses the price by solving

$$
\max _{p} \pi(p, c)=(p-c)[1-F(\bar{v}(p, c))]
$$

The next result characterizes the profit-maximizing pricing policy.

Proposition 1. The profit-maximizing price either satisfies the first-order condition

$$
p^{*}=c+\frac{1-F\left(\bar{v}\left(p^{*}, c\right)\right)}{f\left(\bar{v}\left(p^{*}, c\right)\right) \bar{v}_{p}\left(p^{*}, c\right)},
$$

or solves the zero-loss condition $L\left(p^{0}, c\right)=0$. Consumer conscientiousness constrains the firm's pricing power and profit if it creates a psychological loss at the standard monopoly price $p^{m}$.

Proposition 1 shows that the firm sets the standard monopoly p rice $p^{m}$ satisfying $p^{m}=c+\frac{1-F\left(p^{\underline{m}}\right)}{f\left(p^{m}\right)}$ if consumer conscientiousness does not create a psychological loss at this price, in which case $\bar{v}\left(p^{m}, c\right)=p^{m}$ and $\bar{v}_{p}=1$. The first-order condition then boils down to the standard inverse-elasticity pricing rule $\frac{p^{m}}{p^{m}}=\frac{1}{\varepsilon\left(p^{m}\right)}$. However, if consumer conscientiousness creates a psychological loss at $p^{m}$, then the firm can either lower the price to $p^{0}$ and eliminate the loss or lower the price to $p^{*}$ and impart it on consumers. The relative profitability of these two options depends on the strength of conscientiousness. Intuitively, if the consumers' psychological loss from a deviation from the reference standard (and the resulting demand-reducing effect) is sufficiently large, then it is optimal for the firm to e liminate it by c harging $p^{0}$ and e arn profit $\pi\left(p^{0}, c\right)$. However, if the psychological loss from a deviation from the reference standard is sufficiently small, then it is optimal for the firm to tolerate it and pick the price $p^{*}$ on the "rotated" segment of the demand curve, thereby earning a profit $\pi\left(p^{*}, c\right)$. The rotation of demand occurs because the psychological loss reduces the overall valuations of the product, thereby driving some consumers out of the market (see Figure 1).

We now consider how changes in the reference standard $r$ and the strength of reference dependence $\lambda$ affect profit-maximizing pricing. 
Proposition 2. If the firm tolerates a psychological loss, then the impact of a change in the reference standard $r$ and the strength of reference dependence $\lambda$ on the profit-maximizing price $p^{*}$ is generally ambiguous. Instead, if the firm eliminates the loss, then a more stringent reference standard (a lower $r$ ) and stronger reference dependence (a higher $\lambda$ ) reduce the price $p^{*}$.

Proposition 2 shows how the impact of consumer conscientiousness on the profitmaximizing price depends on the consumers' preference parameters $r$ and $\lambda$. If the psychological loss is small, the impact on the profit-maximizing price depends on whether the relevant parameter change increases the marginal profit of increasing the price, which in turn hinges on the distribution of consumer valuations and the curvature of the loss function. However, if the firm eliminates the psychological loss, then the price impact of stronger consumer conscientiousness is unambiguously determined by the partial derivatives of the loss function with respect to the price and the relevant parameter. Intuitively, if consumer conscientiousness is sufficiently strong, then the firm eliminates the loss to meet the pressure exerted by consumers; if this pressure is reinforced, then the firm needs to further give in on price to meet consumer expectations.

\subsection{Pricing With a Reference Margin}

This section illustrates the impact of consumer conscientiousness on pricing in a setting with linear demand where purchase decisions are affected by a reference margin $\bar{m}$. At a more general level, this illustration provides a formal analysis of dual entitlement (Kahneman, Knetsch and Tversky 1986). We derive the following result.

Corollary 1. Suppose that $v$ is uniformly distributed on $[0, \theta]$, with $\theta>c$, and that the loss function is given by $L(p, c)=\max \{0, \lambda(p-c-\bar{m})\}$, with $\lambda \geq 0$. For a small reference margin $\bar{m} \in\left[0, \frac{\theta-c}{2+\lambda}\right)$, the profit-maximizing price is given by

$$
p^{*}=\frac{\theta+(1+2 \lambda) c+\lambda \bar{m}}{2(1+\lambda)} .
$$

For an intermediate reference margin $\bar{m} \in\left[\frac{\theta-c}{2+\lambda}, \frac{\theta-c}{2}\right)$, it is optimal for the firm to set $p^{0}=c+\bar{m}$. For a large reference margin $\bar{m} \geq \frac{\theta-c}{2}$, it is optimal to set the standard 


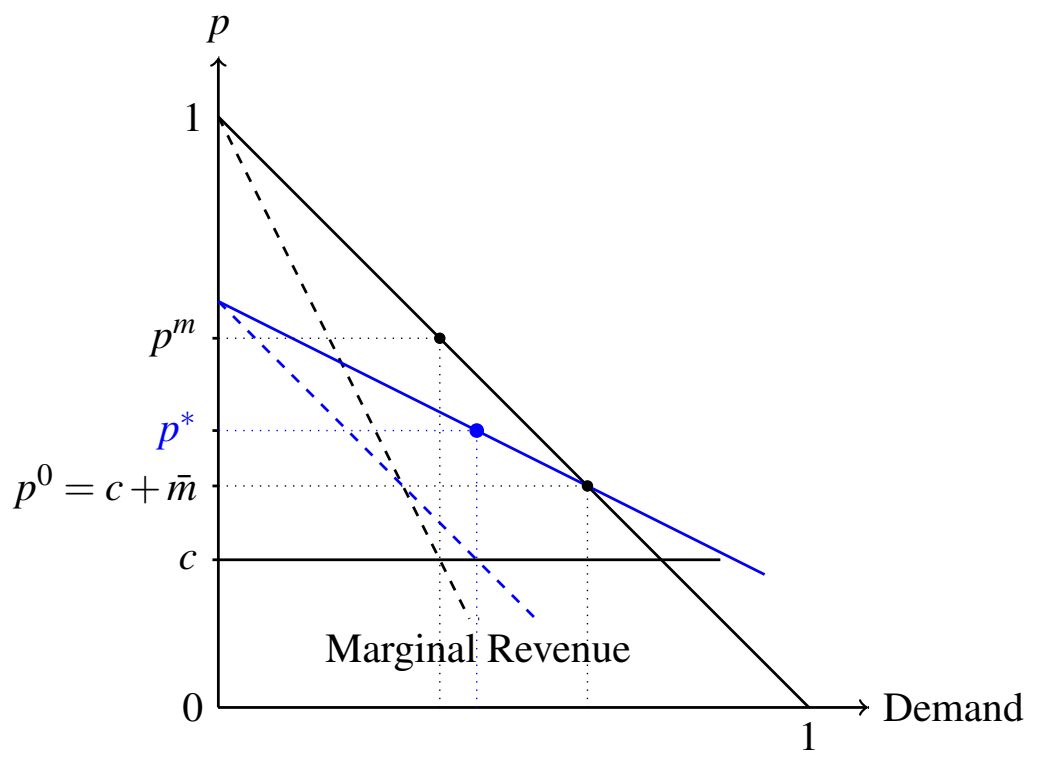

Figure 1: The impact of consumer conscientiousness on demand and marginal revenue, and the corresponding optimal prices for $\theta=1, \lambda=1, \bar{m}=\frac{1}{8}$, and $c=\frac{1}{4}$. The profitmaximizing price is $p^{*}$.

monopoly price $p^{m}=\frac{\theta+c}{2}$. A more stringent reference margin $\bar{m}$ and stronger reference dependence $\lambda$ reduce the profit-maximizing price.

Figure 1 helps to visualize how profit-maximizing pricing works in a linear-demand setting with a reference margin. The conditions in Corollary 1 characterize the optimal pricing policy and show how it is determined by the interplay of the relevant firm and consumer parameters. In particular, Corollary 1 shows that it is optimal for the firm to impart a psychological loss on consumers if the reference margin is small, whereas it is optimal to eliminate the loss and match the reference margin if the latter is at an intermediate level. Unsurprisingly, it is optimal to set the standard monopoly price $p^{m}$ if the reference margin does not affect purchase decisions. Finally, the result shows that stronger reference dependence reduces the pricing power of the firm. The n ext result demonstrates that consumer conscientiousness may eliminate the pricing power altogether.

Corollary 2. If conscientious consumers have markup aversion $(\bar{m}=0)$ and strong reference dependence $(\lambda \rightarrow \infty)$, then the firm is forced to sell at unit cost. 
Corollary 2 shows that, even though a monopolist can make "take-it-or-leave-it" offers to consumers, it effectively lacks market power when deviations from a reference standard that leaves zero profit to the firm are extremely co stly. This result formalizes the notion of "anti-profit beliefs," where consumers feel entitled to the entire surplus (Bhattacharjee, Dana and Baron 2017; Kahneman, Knetsch and Tversky 1986). More broadly, note that this section nests the analysis of the impact of a reference price on profit-maximizing pricing (Buehler and Gärtner 2013; Mazumdar, Raj and Sinha 2005). When consumers know the unit cost, a given reference margin $\bar{m}$ and cost level $c$ correspond to the reference price $\bar{p}=\bar{m}+c$, in which case the loss function boils down to $L(p)=\max \{0, \lambda(p-\bar{p})\}$.

\section{Cost Transparency}

This section extends the analysis to a setting where conscientious consumers do not know the firm's u nit cost with certainty and must therefore form an expectation of the psychological loss. In this case, consumers infer the firm's unit cost from its price and disclosure decisions. We first study the conditions under which it is profit-maximizing for the firm to conceal its unit c o st. Next, we ex amine the conditions under which cost transparency emerges in the marketplace. Throughout, we focus on the interesting case where consumer conscientiousness creates a psychological loss and firms truthfully disclose their cost (Milgrom 2008).

\subsection{Setup}

Suppose that the unit $\operatorname{cost} c_{i}, i \in\{L, H\}$, is known only to the firm, but it is common knowledge that unit cost is high, $c_{H}$, with probability $\phi$, or low, $c_{L}<c_{H}$, with probability $1-\phi$. The firm sets the price and decides whether or not to engage in cost transparency by disclosing its unit $\operatorname{cost} c_{i}$ at an exogenous fixed cost of disclosure $K>0$. Consumers observe these actions by the firm and make their purchase decisions.

Firm strategy involves a price and disclosure decision. We allow for mixed strategies and view the firm's strategy a s a probability distribution over prices $p_{j}$ and disclosure decisions (Stahl and Strausz 2017). Specifically, we let $\sigma_{i}^{u}(p)$ denote the probability that 
a firm with undisclosed unit $\operatorname{cost} c_{i}$ offers the product at price $p$, whereas $\sigma_{i}^{d}(p)$ denotes the probability that a firm with disclosed unit $\operatorname{cost} c_{i}$ sells at price $p$. A strategy of a firm with unit $\operatorname{cost} c_{i}$ is a combination $\sigma_{i}=\left(\sigma_{i}^{u}, \sigma_{i}^{d}\right)$ such that

$$
\sum_{j} \sigma_{i}^{u}\left(p_{j}\right)+\sum_{j} \sigma_{i}^{d}\left(p_{j}\right)=1
$$

If the firm sells at price $p$ and discloses its unit $\operatorname{cost} c_{i}$, then consumers can evaluate the loss $L\left(p, c_{i}\right)$ and buy the product provided that $v \geq \bar{v}\left(p, c_{i}\right)=p+L\left(p, c_{i}\right)$. That is, consumers make purchase decisions under full information. Instead, if the firm does not disclose its unit $\operatorname{cost} c_{i}$, then consumers must form a belief about the latter by interpreting the price $p$ as a signal. In equilibrium, the belief must follow Bayes' rule whenever possible. When facing price $p$, the consumers' belief that cost is high, $\mu(p)$, is consistent with the firm's strategy $\left(\sigma_{L}, \sigma_{H}\right)$ if, for any $\sigma_{i}^{u}(p)>0$,

$$
\mu(p)=\frac{\phi \sigma_{H}^{u}(p)}{\phi \sigma_{H}^{u}(p)+(1-\phi) \sigma_{L}^{u}(p)} .
$$

It is optimal for a consumer with valuation $v$ to purchase if $v \geq \hat{v}(p, \mu(p))$, where

$$
\hat{v}(p, \mu(p))=p+\mu(p) L\left(p, c_{H}\right)+(1-\mu(p)) L\left(p, c_{L}\right)
$$

denotes the valuation of the consumer who is indifferent between purchasing the product or choosing the outside option when unit cost is uncertain. Letting $\sigma(p, \mu(p))$ denote the purchase probability given the price $p$ and the belief $\mu(p)$, with $\sigma=1$ if $v \geq \hat{v}(p, \mu(p))$ and zero otherwise, demand can be derived as

$$
D(p, \mu(p))=\int_{0}^{\infty} \sigma(p, \mu(p)) d F(v)=1-F(\hat{v}(p, \mu(p))) .
$$

Consumer conscientiousness without cost disclosure therefore implies that demand depends on the price and the belief about cost, as consumers must form an expectation of the psychological loss.

Let $\pi_{i}^{u}$ denote the profit of a firm with undisclosed unit cost $c_{i}$. Given the be lief $\mu(p)$ and utility-maximizing consumer behavior, a firm with undisclosed unit $\operatorname{cost} c_{i}$ that offers the product at price $p$ earns profit

$$
\pi_{i}^{u}(p)=\left(p-c_{i}\right)[1-F(\hat{v}(p, \mu(p)))] .
$$


Similarly, a firm that discloses unit $\operatorname{cost} c_{i}$ and offers the product at price $p$ receives the profit

$$
\pi_{i}^{d}(p)=\left(p-c_{i}\right)\left[1-F\left(\bar{v}\left(p, c_{i}\right)\right)\right]-K,
$$

where $K>0$ is the cost of disclosure. Hence, a strategy $\sigma_{i}=\left(\sigma_{i}^{u}, \sigma_{i}^{d}\right)$ generates the expected profit

$$
\pi_{i}\left(\sigma_{i}\right)=\sum_{j} \sigma_{i}^{u}\left(p_{j}\right) \pi_{i}^{u}\left(p_{j}\right)+\sum_{j} \sigma_{i}^{d}\left(p_{j}\right) \pi_{i}^{d}\left(p_{j}\right)
$$

\subsection{Cost Concealment}

We first identify the conditions under which both types of firm choose to conceal their unit cost. Specifically, we study pooling equilibria in which both firm types choose the same price and disclosure strategy $\sigma_{i}$. We solve for Perfect Bayesian Equilibrium (PBE), a combination $\left\{\sigma_{L}^{*}, \sigma_{H}^{*}, \mu^{*}, \sigma^{*}\right\}$ for which the firm's strategy $\left\{\sigma_{L}^{*}, \sigma_{H}^{*}\right\}$ maximizes profit, the consumers' belief $\mu^{*}$ is consistent with the firm's strategy choice, and the consumers' purchase decisions $\sigma^{*}$ maximize utility. With this in mind, we derive our next result.

Proposition 3. Let $\tilde{p}$ denote the profit-maximizing p rice of the high-cost firm given the belief $\mu(p)$, and assume that both types of firm p refer charging $\tilde{p}$ to charging the profit-maximizing price when perceived as the low-cost firm. Then, if the cost of disclosure $K$ satisfies

$$
K \geq\left(\tilde{p}-c_{H}\right)\left[F(\hat{v}(\tilde{p}, \phi))-F\left(\bar{v}\left(\tilde{p}, c_{H}\right)\right)\right]
$$

there exists a unique pure-strategy pooling equilibrium with price $\tilde{p}$ and cost concealment, supported by the beliefs $\mu(\tilde{p})=\phi$ on the equilibrium path and $\mu(p)=0$ for $p \neq \tilde{p}$ off the equilibrium path.

This result shows that there exists an equilibrium in which both types of firm conceal their unit cost. Intuitively, in such a pooling equilibrium the high-cost firm could benefit from disclosing its unit cost by reducing the psychological loss imparted on conscientious consumers (as $L_{c} \leq 0$ ) and thereby boosting demand, but the resulting increase in product market profit - the margin multiplied by sales volume-is too low compared to the cost 
of disclosure. In contrast, the low-cost firm cannot benefit from being transparent: cost disclosure is not only costly, but it also removes the uncertainty about the firm's type, thereby lowering demand and further reducing profit (the psychological loss is higher because consumers no longer entertain the possibility that the firm has high unit cost, which happens with probability $\mu(\tilde{p})=\phi$ in a pooling equilibrium). Overall, this result shows that consumer conscientiousness alone is not sufficient for cost transparency to emerge in the marketplace: what matters is the trade off between the increase in product market profit and the cost of disclosure. Proposition 3 highlights that concealing one's unit cost can be in the best interest of the firm. For instance, Gilead, a pharmaceutical company, is "stubbornly opaque" about the cost to produce Remdesivir, an experimental drug that may help people suffering from COVID-19 recover more quickly, pointing to the broader concern that there may not be sufficient transparency about costs in health care (Mancini and Henderson 2020; O’Brien 2020).

\subsection{Cost Disclosure}

We now turn to the case in which the interaction between the firm and consumers spurs cost transparency. Specifically, we identify the conditions under which only the high-cost firm discloses its unit cost. In such an equilibrium, the type of the firm that does not disclose is correctly inferred from the firm's price and disclosure decisions. The following result holds.

Proposition 4. If the cost of disclosure K satisfies

$$
K<\max _{p}\left(p-c_{H}\right)\left[1-F\left(\bar{v}\left(p, c_{H}\right)\right)\right]-\max _{p} \pi_{H}^{u}(p),
$$

then there exists a unique separating PBE in pure strategies in which the high-cost firm discloses its unit cost and the low-cost firm does not, and the profit-maximizing price of firm $i, i \in\{L, H\}$, satisfies

$$
p_{i}^{*}=c_{i}+\frac{1-F\left(\bar{v}\left(p_{i}^{*}, c_{i}\right)\right)}{f\left(\bar{v}\left(p_{i}^{*}, c_{i}\right)\right) \bar{v}_{p_{i}}\left(p_{i}^{*}, c_{i}\right)} .
$$

Proposition 4 highlights the high-cost firm's motivation to distinguish itself from the low-cost firm by choosing to disclose unit cost. Cost disclosure increases demand, and 
hence product market profit, due to the reduced psychological loss imparted on consumers. If the cost of disclosure is sufficiently small, then revealing unit cost is profitable. In contrast, a low-cost firm cannot benefit from cost disclosure since it entails an extra cost for confirming what consumers anyway expect (namely, that the unit cost is low). Overall, this result provides an explanation for the observation that some firms reveal their unit cost to consumers. For instance, in the apparel industry, Everlane engages in "radical transparency" by disclosing the unit cost of each garment on its website, stating that "we believe our customers have a right to know how much their clothes cost to make.'1 1

\section{Operational Transparency}

Cost is just one characteristic_-albeit a prominent one_of a firm's supply chain. Quite often, firms also provide information about their production process itself (Buell, Kim and Tsay 2017; Mohan, Buell and John 2020). For instance, firms reveal their sustainability efforts or measures taken against the use of child labor. Similarly, claims such as "Made in the USA" reassure the public that a product is produced in accordance with local regulations, in turn suggesting higher production standards than those of offerings sourced internationally (Kong and Rao 2020). To capture the notion of operational transparency, we adapt our analytical framework and consider disclosures about production standards rather than the unit cost.

Specifically, we let $s_{i}, i \in\{L, H\}$, denote the production standard of the supply chain. This standard, known only to the firm, can capture a single attribute or encompass multiple dimensions, in which case $s_{i}$ should be interpreted as an index summarizing the various characteristics of the supply chain. Consumers know that the production standard is high, $s_{H}$, with probability $\phi$, or low, $s_{L}<s_{H}$, with probability $1-\phi$. At price $p$ and known production standard $s_{i}$, consumers experience the psychological loss $L\left(p, s_{i}\right)$ if the firm does not meet the reference standard. The firm sets the price and decides whether or not to engage in operational transparency by disclosing the production standard $s_{i}$ at an exogenous fixed cost of disclosure $K>0$. The following result holds.

\footnotetext{
${ }^{1}$ For details, see https://www . everlane.com/about
} 
Proposition 5. Suppose that consumers care about the production standard of the supply chain. If the cost of disclosure is sufficiently low compared to the increase in product market profit caused by operational transparency, then there exists a unique separating $P B E$ in pure strategies in which the profit-maximizing price is ba sed on production standards and the high-standard firm discloses the characteristics of its supply chain while the low-standard firm does not.

Proposition 5 extends the logic of cost transparency to the analysis of operational transparency and shows that a high-standard firm has a profit motive to distinguish itself from the low-standard firm. The d riving force b ehind this $r$ esult is s imilar to the one driving cost transparency: Conscientious consumers suffer from a higher psychological loss if the production standard is low, which provides an incentive for a firm with a high production standard to disclose how it operates. Profit-maximizing pricing in the separating equilibrium is similar to that under cost transparency and accounts for the psychological loss of conscientious consumers if production standards fall short of "should expectations" (Boulding et al. 1994; Tse and Wilton 1988).

This result provides an explanation for commonly observed business practices in the fashion industry. Everlane not only discloses the unit cost of its garments, but also factors such as fair wages, reasonable hours, and environmental impact for its suppliers. Similarly, Oliver Cabell openly communicates how its products are made, where they are made, and what materials are used, while Kering commits to becoming carbon neutral within its own operations and across the entire supply chain. In the automotive industry, Tesla commits to responsible material sourcing, whereas Volvo commits to being transparent about the supply chain for cobalt by using block chain technology.

However, if the production standard encompasses multiple dimensions, establishing operational transparency can be a challenging and cost-intensive task, especially for firms that have many (successive) upstream suppliers. For instance, in the cotton industry, the "trouble is cotton's convoluted journey from farm to shop" (The Economist 2020). Operational transparency is costly not only because multiple characteristics must be disclosed, but also because links in the supply can be overlooked or hard to assess, which 
creates operational risk for a firm. This is the case, for example, when upstream suppliers rely on forced labor or engage in other abusive practices (Financial Times 2020).

More broadly, our analysis offers guidance for firms on h ow to handle and protect consumer data. If conscientious consumers care for data privacy, operational transparency can be profitable for the firm, whereas violations of data privacy have been shown to create “consumer backlash" (Acquisti, Taylor and Wagman 2016). For instance, to address the need for data privacy, Apple gives consumers control over their information (Apple 2020).

\section{Discussion}

This paper explored how a firm should make price and disclosure decisions in the face of consumers who are sensitive not only to a product's intrinsic features and price, but also to the impact of their purchases on society and the environment. We first studied cost transparency, as conscientious consumers often care about margins. Our analysis showed that a firm should conceal its unit cost if disclosure is sufficiently costly relative to the increase in product market profit caused by cost t ransparency. If disclosure is inexpensive, however, we demonstrated that a firm with a high unit cost can grow demand and profit by being transparent, while a firm with a low unit cost cannot.

Next, we studied operational transparency to account for concerns about ethical and sustainable sourcing. Our analysis showed that, once again, only a high-standard firm can benefit from disclosing specific elements of its production pr ocess. Further, operational transparency is unlikely to be profitable in complex supply chains with many successive upstream suppliers, where the cost of disclosure and operational risk is high.

The remainder of this section elaborates on the implications of our results for firms, consumers, and policy makers. We conclude by discussing some of the limitations of our work and avenues for future research.

\subsection{Implications for Firms}

Firms are increasingly faced with consumers who care about the characteristics of the supply chain. Our analysis suggests that conscientious consumers do not value supply 
chain transparency per se; in fact, they are less inclined to purchase if they learn that key supply chain characteristics fall short of the reference standard. Therefore, as a first step firms should gauge via market research whether engaging in supply chain transparency can enhance demand. The second step is to acknowledge and estimate the trade off between the demand-enhancing effect of supply chain transparency and the cost of disclosure. The fact that supply chain transparency comprises pros and cons implies that a "one size fits all" approach does not lead to the optimal outcome for a profit-maximizing fi rm. As a result, firms with complex international supply chains with multiple layers, for example, will typically find it less profitable to be transparent than firms with less complex supply chains.

It is worth adding that the cost and benefit of transparency should vary across time and markets. On the cost side, developments such as RFID-based technology or block chain technology eases the financial burden of c ertification. On the benefit side, raising consumer awareness and increasing pressure by NGOs and consumer action groups reinforce the benefits of $\mathrm{t} r$ ansparency. Firms should therefore monitor and revise their price and disclosure decisions accordingly. Finally, if the cost of supply chain transparency is prohibitive in certain regions of the world for political or economic reasons, then firms could consider the relocation of their supply chains to better tackle the concerns of conscientious consumers.

\subsection{Implications for Consumers}

Our analysis shows that profit-maximizing firms cater to the preferences of conscientious consumers. To this end, firms adjust their prices and decide whether to engage in supply chain transparency (or relocate their supply chain) to boost demand and profit. In this sense, consumers can pressure firms into meeting their s t andards. For instance, in the extreme case where consumers feel entitled to the full surplus from the transaction and avoid making a purchase if the firm seeks to retain even a small share, the firm's profit can be forced down to zero. Conscientious consumers, therefore, can have a strong impact on firm profitability. 


\subsection{Implications for Policy Makers}

While conscientious consumers are able to effectively discipline the price and disclosure decisions of a firm, their preferences are not necessarily aligned with those of policy makers. For instance, a regulator might want to impose a stricter reference standard or reinforce the strength of reference dependence to further improve the market outcome. To reach these goals, a regulator can try to influence the preferences of conscientious consumers (e.g., by means of a public campaign) or impose its preferences on firms by legal measures (e.g., by imposing minimal standards for ethical and sustainable sourcing).

The so-called "Responsible Business Initiative" in Switzerland, which targets large multinational firms in industries such as commodity trading and mining, provides an example. $\sqrt{2}^{2}$ If the initiative is supported by a majority of the population in a public vote in November 2020, firms "will be liable for human rights abuses and environmental violations caused abroad by companies under their control." However, if the initiative is rejected, a counter-proposal by the parliament will be put in place that requires Swiss companies to disclose nonfinancial information regarding their supply chains, and selected companies will have to conduct human rights and environmental due diligence.

\subsection{Limitations and Future Research}

Future research could study various generalizations of our setting. First, it would be interesting to study how firms make decisions on pricing and supply chain transparency under competition. While pricing in competitive markets is well understood, analyzing pricing and transparency decisions in markets with conscientious consumers is complex. With competition, the disclosure of supply chain characteristics not only informs conscientious consumers, but also leads to information exchange among competitors-with unknown overall effect on consumers, firms, and society. Strategic information exchange among competitors also raises antitrust concerns regarding the possibility of collusion.

Second, future research could consider dynamic decisions on pricing and supply chain transparency. In such a setting, consumers may infer the unit cos (and other relevant

\footnotetext{
${ }^{2}$ For details, see https://corporatejustice.ch/about-the-initiative
} 
supply chain characteristics) from prices observed in the past. Perhaps the simplest and most common example of this is a firm that uses price promotions to spur demand. In a market with conscientious consumers, the price concession is a material benefit, but it also provides information about the likely upper bound of the unit cost. That is, if consumers assume that firms will not discount to the point where they actually lose money on a sale, then the discounted price leads consumers to think that the reference standard is more stringent than they expected, which has its own effect on demand. Knowing this, firms face a more complicated decision with respect to promotional campaigns, as larger discounts supposedly have a larger direct effect on sales and trigger a larger psychological loss.

Third, it might be interesting to consider a setting in which the disclosure of unit costs or other supply chain characteristics informs consumers about unknown product quality. The marketing literature contains a rich set of studies documenting a positive correlation between price levels and perceived quality. This link makes sense because prices are typically observable and they build on unit cost. Yet the cost of producing a product is arguably a more accurate proxy for quality than price is, as the margin included in a price has no bearing on the eventual performance of an offering. This line of research is promising because it would build on asymmetric information about characteristics of the product and the supply chain, thereby connecting two separate strands of the literature.

Finally, it would be interesting to study "ideological consumption," which refers to a setting in which consumers purchase a product or service for ideological reasons even if their intrinsic valuation of the product is lower than the price. In contrast to the approach adopted in this paper (and much of the related literature), this would require that, from the consumers' point of view, gains loom larger than losses.

\section{References}

Acquisti, Alessandro, Curtis Taylor, and Liad Wagman (2006), "The Economics of Privacy," Journal of Economic Literature, 54(2), 442-492. 
Amaldoss, Wilfred, and Chuan He (2018), "Reference-Dependent Utility, Product Variety, and Price Competition," Management Science, 64(9), 4302-4316.

Anderson, Eric T., and Duncan I. Simester (2008), "Does Demand Fall When Customers Perceive That Prices Are Unfair? The Case of Premium Pricing for Large Sizes," Marketing Science, 27(3), 492-500.

Apple (2020), "Privacy" (accessed October 1, 2020). Available at https://www . apple. com/privacy/.

Armstrong, Mark, and John Vickers (2012), “Consumer Protection and Contingent Charges," Journal of Economic Literature, 50(2), 477-493.

Atefi, Yashar, Michael Ahearne, Sebastian Hohenberg, Zachary Hall, and Florian Zettelmeyer (2020), “Open Negotiation: The Back-End Benefits of Salespeople's Transparency in the Front End," Journal of Marketing Research, forthcoming.

Bertini, Marco, and Luc Wathieu (2008), "Research Note-Attention Arousal Through Price Partitioning," Marketing Science, 27(2), 236-246.

Bhattacharjee, Amit, Jason Dana, and Jonathan Baron (2017), “Anti-Profit Beliefs: How People Neglect the Societal Benefits of Profit," Journal of Personality and Social Psychology, 113(5), 671-696.

Bolton, Lisa E., and Joseph W. Alba (2006), "Price Fairness: Good and Service Differences and the Role of Vendor Costs," Journal of Consumer Research, 33(2), 258-265.

Bonroy, Olivier, and Stéphane Lemarié (2012), "Downstream Labeling and Upstream Price Competition," European Economic Review, 56(3), 347-360.

Boulding, William, Ajay Kalra, Richard Staelin, and Valarie A. Zeithaml (1993), “Dynamic Process Model of Service Quality: From Expectations to Behavioral Intentions," Journal of Marketing Research, 30(1), 7-27. 
Bruno, Hernan A., Hai Che, and Shantanu Dutta (2012), "Role of Reference Price on Price and Quantity: Insights from Business-to-Business Markets," Journal of Marketing Research, 49(5), 640-654.

Buchanan, James M. (1954), "Individual Choice in Voting and the Market," Journal of Political Economy, 62(4), 334-343.

Buehler, Stefan, and Dennis L. Gärtner (2013), "Making Sense of Nonbinding Retail-Price Recommendations," American Economic Review, 103(1), 335-359.

Buell, Ryan W., and Michael I. Norton (2011), “The Labor Illusion: How Operational Transparency Increases Perceived Value. Management Science, 57(9), 1564-1579.

Buell, Ryan W., Tami Kim, and Chia-Jung Tsay (2017), "Creating Reciprocal Value Through Operational Transparency," Management Science, 63(6), 1673-1695.

Caplin, Andrew, and Barry Nalebuff (1991), "Aggregation and Imperfect Competition: On the Existence of Equilibrium," Econometrica, 59(1), 25-59.

Chen, Haipeng, Lisa E. Bolton, Sharon Ng, Dongwon Lee, and Dian Wang (2018), "Culture, Relationship Norms, and Dual Entitlement," Journal of Consumer Research, 45(1), 1-20.

Dranove, David, and Ginger Zhe Jin (2010), "Quality Disclosure and Certification: Theory and Practice." Journal of Economic Literature, 48(4), 935-963.

Eyster, Erik, Kristof Madarász, and Pascal Michaillat (2020), "Pricing Under Fairness Concerns," Journal of the European Economic Association, forthcoming.

Gapper, John (2020), "Forced Labour is the Price of a Cheap Cotton T-Shirt." Financial Times (accessed October 27, 2020). Available at https://on.ft.com/3kz8FaC.

Giesler, Markus, and Ela Veresiu (2014), “Creating the Responsible Consumer: Moralistic Governance Regimes and Consumer Subjectivity," Journal of Consumer Research, 41(3), 840-857. 
Guo, Liang (2015), "Inequity Aversion and Fair selling," Journal of Marketing Research, 52(1), 77-89.

Guo, Xiaomeng, and Baojun Jiang (2016), "Signaling Through Price and Quality to Consumers with Fairness Concerns.” Journal of Marketing Research, 53(6), 988-1000.

Guo, Liang, and Ying Zhao (2009), "Voluntary Quality Disclosure and Market Interaction," Marketing Science, 28(3), 488-501.

Harbaugh, Rick, John W. Maxwell, and Beatrice Roussillon (2011), "Label Confusion: The Groucho Effect of Uncertain Standards," Management Science, 57(9), 1512-1527. Heidhues, Paul, and Botond Kőszegi (2008), “Competition and Price Variation When Consumers are Loss Averse," American Economic Review, 98(4), 1245-1268.

Jiang, Baojun, K. Sudhir, and Tianxin Zou (2020), "Effects of Cost-Information Transparency on Intertemporal Price Discrimination," Productions and Operations Management, forthcoming.

Kahneman, Daniel, Jack L. Knetsch, and Richard Thaler (1986), "Fairness as a Constraint on Profit Seeking: Entitlements in the Market," American Economic Review, 76(4), $728-741$.

Karle, Heiko, Georg Kirchsteiger, and Martin Peitz (2015), "Loss Aversion and Consumption Choice: Theory and Experimental Evidence," American Economic Journal: Microeconomics, 7(2), 101-120.

Karle, Heiko, and Martin Peitz (2014), "Competition Under Consumer Loss Aversion," Rand Journal of Economics, 45(1), 1-31.

Kong, Xinyao, and Anita Rao (2020), “Do Made in USA Claims Matter?” Marketing Science, forthcoming.

Lim, Wei Shi, Vincent Mak, Christopher S. Tang, and KC Raghabendra (2018), “Adopting Cost Transparency as a Marketing Strategy: Analytical and Experimental Exploration (September 21, 2018). Available at https://ssrn. com/abstract=3252823 
Mancini, Donato P., and Richard Henderson (2020), “CureVac Vows 'Ethical Margin' on Price of Covid-19 Vaccine," Financial Times (accessed October 26, 2020). Available at https://on.ft.com/3jw4UBu.

Marshall, Donna, Lucy MacCarthy, Paul McGrath, and Fiona Harrigan (2016), "What's Your Strategy for Supply Chain Disclosure?” MIT Sloan Management Review, 57(2), $37-45$.

Mazumdar, Tridib, Sevilimedu P. Raj, and Indrajit Sinha (2005), "Reference Price Research: Review and Propositions," Journal of Marketing, 69(4), 84-102.

Milgrom, Paul (2008), “What the Seller Won't Tell You: Persuasion and Disclosure in Markets," Journal of Economic Perspectives, 22(2), 115-131.

Mohan, Bhavya, Ryan W. Buell, and Leslie K. John (2020), "Lifting the Veil: The Benefits of Cost Transparency," Marketing Science, forthcoming.

Morwitz, Vicki G., Eric A. Greenleaf, and Eric J. Johnson (1998), "Divide and Prosper: Consumers' Reactions to Partitioned Prices," Journal of Marketing Research, 35(4), $453-463$.

O’Brien, Timothy L. (2020), “\$600 or \$3,120? Gilead Puts a Price Tag on Covid-19 Relief," Bloomberg, (accessed October 1, 2020). Available at https://bloom.bg/3ir6kNq.

Rabin, Matthew (1993), "Incorporating Fairness Into Game Theory and Economics," American Economic Review, 83(5), 1281-1302.

Rotemberg, Julio J. (2011), "Fair Pricing," Journal of the European Economic Association, 9(5), 952-981.

Santana, Shelle, Steven K. Dallas, and Vicki G. Morwitz (2020), "Consumer Reactions to Drip Pricing," Marketing Science, 39(1), 188-210.

Schwartz, John (2017, August 23). "Exxon Misled the Public on Climate Change, Study Says" (accessed September 28, 2020), The New York Times. Available at https: //nyti.ms/3mY3lzc. 
Sodhi, ManMohan S., and Christopher S. Tang (2019), "Research Opportunities in Supply Chain Transparency," Production and Operations Management, 28(12), 2946-2959.

Stahl, Konrad, and Roland Strausz (2017), “Certification and Market Transparency.” The Review of Economic Studies, 84(4), 1842-1868.

Thaler, Richard (1985), "Mental Accounting and Consumer Choice," Marketing Science, 4(3), 199-214.

The Economist (2020, October 25), "Can the Stain of Forced and Child Labour Be Removed From Cotton?" (accessed October 25, 2020). Available at https://econ. st/37XjHTZ.

Tse, David K., and Peter C. Wilton (1988), "Models of Consumer Satisfaction Formation: An Extension," Journal of Marketing Research, 25(2), 204-212.

Wu, Yue, Kaifu Zhang, and Jinhong Xie (2020), "Bad Greenwashing, Good Greenwashing: Corporate Social Responsibility and Information Transparency," Management Science, 66(7), 3095-3112.

Xia, Lan, Kent B. Monroe, and Jennifer L. Cox (2004), "The Price is Unfair! A Conceptual Framework of Price Fairness Perceptions," Journal of Marketing, 68(4), 1-15.

Zhou, Jidong (2011), "Reference Dependence and Market Competition," Journal of Economics and Management Strategy, 20(4), 1073-1097.

\section{Appendix}

Proof of Lemma 1 The price elasticity of demand can be written as

$$
\varepsilon(p, c)=-\frac{p D_{p}(p, c)}{D(p, c)}=\frac{p f(\bar{v}(p, c)) \bar{v}_{p}(p, c)}{1-F(\bar{v}(p, c))},
$$

where $\bar{v}_{p}(p, c)=1+L_{p}(p, c) \geq 1$. Assumption 2 implies that the Mills ratio $\frac{1-F}{f}$ is non-increasing in price. Consequently, demand is more elastic than in the absence of consumer conscientiousness. 
Proof of Proposition 1 Clearly, it is optimal for the firm to charge the standard monopoly price $p^{*}=p^{m}$ satisfying the necessary and sufficient first-order condition

$$
p^{m}=c+\frac{1-F\left(p^{m}\right)}{f\left(p^{m}\right)}
$$

if consumer conscientiousness does not create a loss at $p^{m}$. Instead, if consumer conscientiousness creates a loss at the standard monopoly price, the firm can choose among two options: charge the highest price $p^{0}$ that solves $L\left(p^{0}, c\right)=0$ or set the price $p^{*}=p^{r}$ satisfying the necessary and sufficient first-order condition

$$
1-F\left(\bar{v}\left(p^{r}, c\right)\right)-\left(p^{r}-c\right) f\left(\bar{v}\left(p^{r}, c\right)\right) \bar{v}_{p}\left(p^{r}, c\right)=0,
$$

which can be rearranged as

$$
p^{r}=c+\frac{1-F\left(\bar{v}\left(p^{r}, c\right)\right)}{f\left(\bar{v}\left(p^{r}, c\right)\right) \bar{v}_{p}\left(p^{r}, c\right)} .
$$

Letting $\pi\left(p^{0}, c\right)$ and $\pi\left(p^{r}, c\right)$ denote the corresponding optimized profit, the optimal price is given by $p^{+}=\arg \max _{p \in\left\{p^{0}, p^{r}\right\}} \pi(p, c)$.

To establish that consumer conscientiousness reduces profit, first note that $p^{0}<p^{m}$ and, by optimality of the unrestricted monopoly price, $\pi\left(p^{0}, c\right)<\pi\left(p^{m}, c\right)$. To show that $p^{r}<p^{m}$, suppose contrary to the assumption that $L\left(p^{r}, c\right)>0$ and $p^{r} \geq p^{m}$, which implies $\bar{v}\left(p^{r}, c\right)=p^{r}+L\left(p^{r}, c\right)>$ $p^{r} \geq p^{m}$. In addition, log-concavity of the demand function implies that the Mills ratio $\frac{1-F}{f}$ is non-increasing in $p$. Taken together, this yields

$$
p^{r}=c+\frac{1-F\left(\bar{v}\left(p^{r}, c\right)\right)}{f\left(\bar{v}\left(p^{r}, c\right)\right) \bar{v}_{p}\left(p^{r}, c\right)}<c+\frac{1-F\left(p^{m}\right)}{f\left(p^{m}\right)}=p^{m},
$$

a contradiction. Finally,

$$
\begin{aligned}
\pi\left(p^{m}, c\right) & \equiv\left(p^{m}-c\right)\left[1-F\left(p^{m}, c\right)\right] \\
& \geq\left(p^{r}-c\right)\left[1-F\left(p^{r}, c\right)\right] \\
& \geq\left(p^{r}-c\right)\left[1-F\left(\bar{v}\left(p^{r}\right), c\right)\right] \\
& \equiv \pi\left(p^{r}, c\right),
\end{aligned}
$$

which shows that profit under consumer conscientiousness cannot exceed the standard monopoly profit. 
Proof of Proposition 2 In an interior solution, the optimal price $p^{*}$ satisfies the first-order condition in A.2, which can more compactly be written as $\pi_{p}\left(p^{*}(x) ; x\right)=0$ where $x \in\{r, \lambda\}$. Applying the implicit function theorem yields

$$
\frac{d p^{*}(x)}{d x}=-\frac{\pi_{x p}\left(p^{*}(x) ; x\right)}{\pi_{p p}\left(p^{*}(x) ; x\right)}
$$

where $\pi_{p p}<0$ by the second-order condition. Hence, the sign of $\frac{d p(x)}{d x}$ in A.4. corresponds to the sign of $\pi_{x p}$.

Using Assumption 1, differentiating (A.2) with respect to $r$ yields

$$
\pi_{r p}=-f\left(\bar{v}\left(p^{*}, c\right)\right) L_{r}-\left(p^{*}-c\right)\left[f^{\prime}\left(\bar{v}\left(p^{*}, c\right)\right) L_{r}\left(1+L_{p}\right)+f\left(\bar{v}\left(p^{*}, c\right)\right) L_{r p}\right] .
$$

Therefore, if $L_{r p}$ is sufficiently positive, the second term in $\mathrm{A} .5$ is positive and dominates the first term, which implies that $\frac{d p(r)}{d r}<0$ and thus that a more stringent reference standard $r$ increases price. Likewise, differentiating A.2 with respect to $\lambda$ yields

$$
\pi_{\lambda p}=-f\left(\bar{v}\left(p^{*}, c\right)\right) L_{\lambda}-\left(p^{*}-c\right)\left[f^{\prime}\left(\bar{v}\left(p^{*}, c\right)\right) L_{\lambda}\left(1+L_{p}\right)+f\left(\bar{v}\left(p^{*}, c\right)\right) L_{\lambda p}\right] .
$$

Hence, if $L_{\lambda p}$ is sufficiently negative, the second term in (A.6) is positive and dominates the first term, in which case $\frac{d p(\lambda)}{d \lambda}>0$.

If the firm eliminates the loss, the profit-maximizing price satisfies $L\left(p^{0}, c\right)=0$. Applying the implicit function theorem yields

$$
\frac{d p^{0}}{d r}=-\frac{L_{r}}{L_{p}} \geq 0, \quad \frac{d p^{0}}{d \lambda}=-\frac{L_{\lambda}}{L_{p}} \leq 0,
$$

where the signs follow from Assumption 1 .

Proof of Corollary 1 Under the uniform assumption, $F(\bar{v}(p, c))=\frac{\bar{v}(p, c)}{\theta}$. Demand can be derived from (2) by substitution and is given by $D(p, c)=(1 / \theta)[\theta+\lambda(\bar{m}+c)-(1+\lambda) p]$.

The standard monopoly price follows from A.1 and is given by $p^{m}=\frac{\theta+c}{2}$. Setting $p^{m}$ is optimal if $L\left(p^{m}, c\right) \leq 0$, that is, as long as $\bar{m} \geq \frac{\theta-c}{2}$. For reference margins below this threshold, the firm can either set $p^{0}=\bar{m}+c$ to eliminate the loss or charge

$$
p^{*}=\frac{\theta+(1+2 \lambda) c+\lambda \bar{m}}{2(1+\lambda)},
$$

which follows from $(A .3)$. The corresponding optimized profit are given by

$$
\pi\left(p^{0}, c\right)=\bar{m}\left(1-\frac{c+\bar{m}}{\theta}\right)
$$


and

$$
\pi\left(p^{*}, c\right)=\frac{(\theta-c+\lambda \bar{m})^{2}}{4 \theta(1+\lambda)},
$$

respectively. Creating a loss and charging the price $p^{*}$ is optimal if and only if

$$
\pi\left(p^{*}, c\right)-\pi\left(p^{0}, c\right)=\frac{(\theta-c-(2+\lambda))^{2}}{4 \theta(1+\lambda)} \geq 0,
$$

which holds if the reference margin satisfies $\bar{m} \leq \frac{\theta-c}{2+\lambda}$. Finally, the comparative statics results regarding $p^{*}$ immediately follow from Proposition 2 ;

$$
\frac{d p^{*}}{d \bar{m}}=\frac{\lambda}{2(1+\lambda)}>0
$$

and

$$
\frac{d p^{*}}{d \lambda}=-\frac{\theta-c+\lambda \bar{m}}{2(1+\lambda)^{2}}<0
$$

as $\theta-c>0$ by assumption.

Proof of Corollary 2 If $\bar{m}=0$ and $\lambda \rightarrow \infty$, then Proposition 1 implies that $p^{0}=c$, which means that the firm is forced to sell at unit cost.

Proof of Proposition 3 In a pooling equilibrium in which the firms use the same strategy $\sigma_{i}$, the consumers cannot improve their prior information from observing firm strategy; hence (4) implies that $\mu(\tilde{p})=\phi$, where $\tilde{p}=\arg \max _{p} \pi_{H}^{u}(p)$. When observing the price $\tilde{p}$, the purchase condition (5) reads

$$
v \geq \hat{v}(\tilde{p}, \phi)=\tilde{p}+\phi L\left(\tilde{p}, c_{H}\right)+(1-\phi) L\left(\tilde{p}, c_{L}\right) .
$$

The corresponding demand is denoted as $D(\tilde{p}, \phi)=1-F(\hat{v}(\tilde{p}, \phi))$.

A firm with undisclosed unit $\operatorname{cost} c_{i}$ that offers the product at price $\tilde{p}$ receives the profit

$$
\pi_{i}^{u}(\tilde{p})=\left(\tilde{p}-c_{i}\right)[1-F(\hat{v}(\tilde{p}, \phi))]
$$

whereas a firm that discloses unit $\operatorname{cost} c_{i}$ and offers the product at price $\tilde{p}$ receives the profit

$$
\pi_{i}^{d}(\tilde{p})=\left(\tilde{p}-c_{i}\right)\left[1-F\left(\bar{v}\left(\tilde{p}, c_{i}\right)\right)\right]-K
$$

Consequently, the firm with unit cost $c_{i}$ does not disclose its cost if $\pi_{i}^{u}(\tilde{p}) \geq \pi_{i}^{d}(\tilde{p})$, that is, if

$$
K \geq\left(\tilde{p}-c_{i}\right)\left[F(\hat{v}(\tilde{p}, \phi))-F\left(\bar{v}\left(\tilde{p}, c_{i}\right)\right)\right] .
$$


Since $\bar{v}\left(\tilde{p}, c_{L}\right)>\hat{v}(\tilde{p}, \phi)>\bar{v}\left(\tilde{p}, c_{H}\right)$, cost transparency increases demand (and hence profit) for the high-cost firm, whereas the opposite holds for the low-cost firm. To support the pooling equilibrium, we assume off-equilibrium beliefs $\mu(p)=0$ for $p \neq \tilde{p}$ and $\pi_{i}^{u}(\tilde{p}) \geq\left(p-c_{i}\right)\left[1-F\left(\hat{v}\left(p, c_{L}\right)\right)\right]$ for any $p$ and $i=L, H$ to prevent profitable deviations from the unique equilibrium price $\tilde{p}$.

Proof of Proposition 4 Let the high-cost firm's strategy be the pure strategy $\sigma_{H}^{d}\left(p_{H}\right)=1$ and the low-cost firm's strategy the pure strategy $\sigma_{L}^{u}\left(p_{L}\right)=1$. Moreover, let the consistent Bayesian belief along the equilibrium path be $\mu(p)=0$ for all $p$ (note that we consider a separating strategy where consistent beliefs require that consumers cannot believe that, under uncertainty, the firm can have high cost). Then, the high-cost firm discloses its unit cost if

$$
\begin{aligned}
\max _{p} \pi_{H}^{d}(p) & =\max _{p}\left(p-c_{H}\right)\left[1-F\left(\bar{v}\left(p, c_{H}\right)\right)\right]-K \\
& >\max _{p}\left(p-c_{H}\right)[1-F(\hat{v}(p, 0))] \\
& =\max _{p} \pi_{H}^{u}(p),
\end{aligned}
$$

that is, if

$$
K<\max _{p}\left(p-c_{H}\right)\left[1-F\left(\bar{v}\left(p, c_{H}\right)\right)\right]-\max _{p} \pi_{H}^{u}(p) .
$$

In contrast, the low-cost firm strictly prefers non-disclosure since

$$
\begin{aligned}
\max _{p}, \pi_{L}^{u}(p) & =\max _{p}\left(p-c_{L}\right)[1-F(\hat{v}(p, 0))] \\
& >\max _{p}\left(p-c_{L}\right)\left[1-F\left(\bar{v}\left(p, c_{L}\right)\right)\right]-K \\
& =\max _{p} \pi_{L}^{d}(p)
\end{aligned}
$$

for any $K>0$. Since consumers correctly infer the type of the firm, the profit-maximizing price is characterized by the pricing rule in (A.3) derived under full information in Proposition 1 .

The equilibrium is unique because (i) the firm cannot $\mathrm{g}$ ain from changing the price when disclosing unit cost with probability 1 , and (ii) cannot gain from disclosing unit cost with probability less than 1 . To see the latter, consider

$$
\pi_{H}^{u}(p)=\left(p-c_{H}\right)[1-F(\hat{v}(p, \mu(p)))]
$$

and observe that, for any price $p$, reducing $\sigma_{H}^{d}(p)$ below 1 increases the probability weight $1-\mu(p)$ that consumers attach to the firm having low c ost. Therefore, demand is lower at any price $p$, which reduces profit. 
Proof of Proposition 5 Let $\sigma_{i}^{u}(p)$ denote the probability that a firm with an undisclosed production standard $s_{i}$ charges price $p$. In a separating equilibrium, $\sigma_{H}^{d}\left(p_{H}\right)=1$ and $\sigma_{L}^{u}\left(p_{L}\right)=1$. Drawing on the proof of Proposition 4, the high-cost firm discloses its production standard if

$$
\begin{aligned}
\max _{p} \pi_{H}^{d}(p) & =\max _{p}\left(p-c_{H}\right)\left[1-F\left(\bar{v}\left(p, s_{H}\right)\right)\right]-K \\
& >\max _{p}\left(p-c_{H}\right)[1-F(\hat{v}(p, 0))] \\
& =\max _{p} \pi_{H}^{u}(p),
\end{aligned}
$$

that is, if

$$
K<\max _{p}\left(p-c_{H}\right)\left[1-F\left(\bar{v}\left(p, s_{H}\right)\right)\right]-\max _{p} \pi_{H}^{u}(p) .
$$

In contrast, the low-cost firm will not disclose its production standard because it has no impact on demand but reduces profit by $K$. 